\title{
A influência da liderança, cultura, estrutura e comunicação organizacional no processo de implantação do planejamento estratégico
}

\author{
The influence of leadership, culture, structure and organizational communication in the \\ implementation process of strategic planning
}

\author{
Juliane Ines Di Francesco Kich ${ }^{1}$ \\ Maurício Fernandes Pereira ${ }^{2}$
}

\section{Resumo}

O presente artigo tem o objetivo de avaliar como os fatores organizacionais, estrutura, liderança, cultura e comunicação influenciam no processo de implantação do Planejamento Estratégico, através de um estudo de caso. O embasamento teórico que norteou a pesquisa utilizou-se dos discursos sobre o Planejamento Estratégico, com foco no seu processo de implantação, assim como o que foi publicado sobre cultura, estrutura, liderança e comunicação e o envolvimento desses temas com o Planejamento Estratégico. Tais referenciais auxiliaram no entendimento desses conceitos no campo de estudo. A pesquisa se caracteriza como um estudo de caso único, com enfoque qualitativo, em que foram utilizados como instrumentos de coleta de dados: análise documental, entrevistas semiestruturadas em profundidade, questionário e observação sistemática; os dados foram analisados de forma qualitativa. A empresa analisada foi a Santa Luzia Laboratório Médico, devido a sua relevância na área em que atua. Por meio dos dados coletados, pode-se observar que para uma empresa implantar seu Planejamento Estratégico de forma eficaz, é preciso que tal planejamento esteja alinhado com sua cultura e integrado a sua estrutura, além de contar com uma comunicação eficaz e com a presença na organização de uma liderança envolvida no processo; esses aspectos foram citados na teoria e encontrados no estudo empírico. Pode-se concluir que, apesar de estarem integrados entre si, os fatores organizacionais estudados - estrutura, cultura, liderança e comunicação - atingiram o processo do Planejamento Estratégico na empresa analisada em diferentes intensidades, tanto no que tange à contribuição para sua efetiva implantação, quanto no que diz respeito a determinadas limitações.

Palavras-chave: Planejamento. Estratégia. Implantação.

\section{Abstract}

This article aims to evaluate how factors organizational structure, leadership, culture and communication influence the implementation process of strategic planning, through a case study. The theoretical framework that guided the research used discourse on strategic planning, focusing on its deployment process, as well as posted on culture, structure, leadership and communication and involvement with strategic planning, such references helped in understanding these concepts in the field -work. The research is characterized as a single case study with qualitative approach, where they were used as instruments of data collection: document analysis, semi-structured in-depth questionnaire and systematic observation, data were analyzed qualitatively. The company analyzed was the Santa Luzia Medical Laboratory, for their

Artigo submetido em 24 de junho de 2010 e aceito para publicação em 26 de novembro de 2010.

${ }^{1}$ Mestre em Administração pela Universidade Federal de Santa Catarina. Endereço: Douglas Seabra Levier, 163, Bloco F, apto: 406, Carvoeira, CEP 88040-410, Florianópolis - SC, Brasil. E-mail: julikich@gmail.com

2 Doutor em Engenharia de Produção pela Universidade Federal de Santa Catarina. Endereço: Universidade Federal de Santa Catarina, Centro Sócio-Econômico, Departamento de Ciências da Administração, Campus Universitário, Trindade, CEP 88040-900, Florianópolis - SC, Brasil. E-mail: mfpcris@gmail.com 
relevance in the area in which it operates. Through the data collected, it can be seen that for a company to deploy its strategic planning effectively, the latter must be aligned with its culture and its integrated structure, and rely on effective communication and the presence in the organization of leadership involved in the process, those aspects that were mentioned in the theory and found in the empirical study. It can be concluded that although they are integrated, the organizational factors studied - structure, culture, leadership and communication - has reached the strategic planning process in the company analyzed with different intensities, both in terms contribution to its effective implementation, as in with respect to certain limitations.

Keywords: Planning. Strategy. Implementation.

\section{Introdução}

As necessidades de transformação e as instabilidades, que nos dias de hoje envolvem o mundo dos negócios, provocam efeitos cada vez mais intensos em todos os ramos empresariais. As organizações estão atuando em um mundo no qual não exercem mais controle (DE GEUS, 2000). Para enfrentar tal conjuntura, é imprescindível que as empresas desenvolvam maior sensibilidade em relação ao meio ambiente e aprimorem a capacidade de prever o futuro e a agilidade de tomar decisões, pois quanto mais demorada a tomada de decisão, menor será o número de opções disponíveis (BOSSIDY, 2005).

O processo de Planejamento Estratégico se constitui em uma ferramenta organizacional que serve de apoio para a tomada de decisão e para a interpretação do ambiente em que a organização está inserida. Kaplan e Beinhocker (2003), Semler (1988) e Robbins (1978) consideram o Planejamento Estratégico uma das tarefas mais importantes dos executivos, já que o planejamento prepara os tomadores de decisão das organizações para agirem adequadamente diante dos inevitáveis momentos de desafio que o mercado impõe.

São muitos os estudos que demonstram que o Planejamento Estratégico é a ferramenta gerencial mais utilizada pelas empresas. Em especial, a empresa de consultoria Bain \& Company, desde 1993, estuda o assunto e a cada pesquisa divulga os resultados por meio de um documento denominado "Ferramentas de Gestão" (RIGBY e BILODEAU, 2007). Em sua última divulgação, essa empresa fez um estudo com 1.221 executivos globais - 101 deles brasileiros - para saber quais ferramentas tornam-se mais importantes para seus negócios e quais são suas prioridades. O estudo aponta que Planejamento Estratégico é a ferramenta número 1 entre as dez mais utilizadas em todo o mundo (América do Norte, América Latina e Europa), com exceção da região Ásia-Pacífico que a coloca em segundo lugar. Os pesquisadores ainda incluíram o Planejamento Estratégico no grupo que denominaram "Ferramentas de Impacto", pois foi conceituado acima da média em várias indústrias, tanto em termos de utilização, quanto de satisfação.

$\mathrm{Na}$ literatura especializada da área são muitas as teorias e recomendações sobre os requisitos de um eficaz e eficiente planejamento e a formulação da estratégia. Os administradores, em sua maioria, já conhecem uma gama de técnicas e modelos de planejamento e sabem utilizá-los de maneira eficaz. No entanto, o problema se apresenta quando chega o momento de agir e colocar as estratégias definidas em prática, ou seja, o momento de implantar o plano estratégico.

Segundo Hrebiniack (2006), muitas empresas focam sua atenção somente no processo de formulação das estratégias e negligenciam a execução. Eles não compreendem que o planejamento e sua implantação são interdependentes, pois um afeta o outro.

Dessa forma, vários executivos passam muito tempo aprendendo e disseminando todas as novas técnicas administrativas que surgem, mas falham em entendê-las e colocá-las em prática, isso frequentemente acontece com o Planejamento Estratégico (BOSSIDY e CHARAN, 2002). Portanto, por mais que as estratégias tenham sido bem escolhidas, elas fracassarão se não houver uma boa implantação 
(WHITTINGTON, 2002), como afirma Ackoff (1982, p. 60), "um plano tem pouco valor, se a organização a que se destina não é capaz de executá-lo”.

Sob essa mesma perspectiva, Brenes, Mena e Molina (2008) afirmam que a elaboração da estratégia não é um fim em si; pelo contrário, é apenas um meio para esse fim, pode-se perceber, então, que a formulação da estratégia é apenas o primeiro passo de uma longa viagem.

Assim sendo, para viabilizar sua execução, o Planejamento Estratégico acaba por integrar outros sistemas organizacionais, muitas vezes modificando ou sendo modificado por tais sistemas, visando à sua implantação efetiva.

A presença de uma liderança que acredita na implantação do Planejamento Estratégico faz com que as coisas aconteçam e é primordial para o seu sucesso (TREGOE e ZIMMERMAN, 1984; ULRICH, 2001; BOSSIDY, 2005; HREBINIACK, 2006), assim como a presença de uma cultura forte voltada à execução e alinhada com os métodos da implantação do Planejamento Estratégico influenciam na sua eficácia (SEMLER, 1988; FREITAS, 1991; PEREIRA e CUNHA, 2004; BOSSIDY e CHARAN, 2002; HREBINIACK, 2006).

Nesse sentido, o Planejamento Estratégico, para ser implantado de forma eficaz, precisa estar integrado à estrutura da organização (ACKOFF, 1982; TREGOE e ZIMMERMAN, 1984; HALL, 1984; CERTO e PETER, 1993; MINTZBERG, 2003; HREBINIACK, 2006). Ainda, o compartilhamento das informações e a transferência de conhecimento também influenciam na execução, ou seja, o sistema de comunicação da empresa atua efetivamente na ação (BEÓN, 1992; BOSSIDY e CHARAN, 2002; BUENO, 2003; HREBINIACK, 2006).

Sendo assim, o objetivo deste trabalho é realizar uma revisão bibliográfica acerca das pesquisas existentes sobre o tema, de modo a compreender como estes fatores - liderança, cultura, estrutura e comunicação influenciam na condução do processo de implantação do Planejamento Estratégico. E, logo após, devido à oportunidade de olhar de forma aprofundada esse processo na Empresa Santa Luzia Laboratório Médico, verificar como tais elementos estão influenciando, de forma positiva ou negativa, a implantação do seu Planejamento Estratégico; isso suscita a seguinte pergunta de pesquisa: como a liderança, cultura, estrutura e comunicação organizacional influenciam no processo de implantação do Planejamento Estratégico da Empresa Santa Luzia Laboratório Médico?

\section{Referencial Teórico}

\section{Planejamento estratégico e o seu processo de implantação}

Antes de definir Planejamento Estratégico é importante entender o sentido dos termos "planejamento" e "estratégia" na administração. Para Ackoff (1982, p. 1), "planejamento é a definição de um futuro desejado e dos meios eficazes de alcançá-lo", o que significa pensamento e controle desse futuro, o que torna as empresas aptas a sobreviverem no ambiente altamente dinâmico em que estão inseridas.

A palavra "estratégia" significa literalmente "a arte do general", pois deriva da palavra grega strategos, que significa "general". Na Grécia Antiga, "estratégia" significava: tudo o que general faz, ou seja, essa palavra estava ligada à questão militar, em cujos termos, "estratégia é a ciência dos movimentos guerreiros fora do campo de visão do general" (OLIVEIRA, 2001a, p. 25).

Na literatura administrativa, o termo estratégia é definido sob diferentes enfoques, por diversos autores. Para Mintzberg (1998), as estratégias representam o que deve ser feito para que a empresa sobreviva. Mintzberg, 
Lampel e Ahlstrand (2000) definiram dez grandes linhas ou escolas de pensamento estratégico: escola da concepção, do planejamento, do posicionamento, do espírito empreendedor, cognitiva, do aprendizado, do poder, da cultura empresarial, do ambiente e da configuração. Ao reconhecer os múltiplos conceitos da palavra estratégia, Mintzberg (2001) também a apresenta com base em cinco definições: estratégia como plano, pretexto, padrão, posição e perspectiva.

Whittington (2002) corrobora com a perspectiva de Mintzberg (2001), quando afirma que a palavra estratégia possui diferentes conceitos, e ele a apresenta sob a abordagem de quatro formas genéricas: clássica, evolucionista, processual e sistêmica. Já Porter (1999, p.73) argumenta que a estratégia consiste em uma forma de fixar limites, fator que acelera o crescimento das organizações, por isso, ele a define assim: "estratégia é a criação de compatibilidade entre as atividades da empresa. Seu êxito depende do bom desempenho de muitas atividades - e não apenas de umas poucas - e da integração entre elas. Se não houver compatibilidade entre as atividades, não existirá uma estratégia diferenciada e a sustentabilidade será mínima."

French (2009) critica as definições do termo "estratégia" na literatura por considerar a existência de uma grande distância do uso do termo no mundo acadêmico e no mundo empresarial. O autor acredita que esse problema é agravado devido à existência de diferentes escolas de pensamento, as quais propõem sofisticadas teorias, cada qual usando sua terminologia de forma ligeiramente diferente uma da outra, o que embora não pareça ser problemático para os estudiosos, se apresenta como uma dificuldade para os profissionais do mundo dos negócios.

Contudo, o termo "estratégia" basicamente significa o caminho escolhido, as ações estabelecidas e adequadas para atingir os objetivos da organização.

Dessa forma, o Planejamento Estratégico é definido por Robbins $(1978$, p. 35) como

"a determinação antecipada dos objetivos a serem atingidos e dos meios pelos quais esses objetivos devem ser atingidos [...] é a decisão de o que fazer, como fazê-lo e quem deverá fazê-lo."

A elaboração de um Plano Estratégico, de acordo com a metodologia de Pereira (2010), se realiza através da elaboração das seguintes etapas: declaração de valores, missão, visão, fatores críticos de sucesso, análise externa, análise interna, questões estratégicas, estratégias e ações estratégicas.

A organização que realiza o Planejamento Estratégico conta com uma série de vantagens (PEREIRA, 2007). Ackoff (1982), De Geus (1997), Colenci e Guerruini (2003) e Kaplan e Beinhocker (2003) destacam a utilização do Planejamento Estratégico como um processo de aprendizagem organizacional que facilita a evolução organizacional.

Entretanto, o Planejamento Estratégico também apresenta algumas limitações, entre elas destaca-se a dificuldade das organizações de fazer com que todos os seus níveis absorvam a ideia do plano, ou seja, é um desafio transformar o Planejamento Estratégico em pensamento estratégico. Amoroso (2002, p. 45) define o pensamento estratégico como "a rede de interconexões entre processos de observação e processamento da informação, que envolve percepção, razão e intuição".

Com isso, pode-se perceber que o Planejamento Estratégico não deve ser considerado apenas como uma afirmação das aspirações da empresa, pois inclui também o que deve ser feito para transformar tais aspirações em realidade, ou seja, faz parte dele o seu processo de implantação (OLIVEIRA, 2001b).

Hrebiniack (2006) considera o processo de implantação fundamental para o sucesso do Planejamento Estratégico. Whittington (2002) acredita que as estratégias, por mais que sejam bem escolhidas podem fracassar, se não ocorrer uma boa implantação; entretanto, Bossidy e Charan (2002, p. 29) concluem que, no seu sentido fundamental, "executar é um processo sistemático de discussão exaustiva dos comos e quês, 
questionando, levando adiante o que foi decidido e assegurando que as pessoas terão sua responsabilidade específica pela execução."

Nesse sentido, Bossidy (2005) apresenta como a maior causa do fracasso das empresas a incapacidade de elas executarem suas ideias e estratégias, uma vez que há falta de disciplina para criar, promover e executar um sistema integrado que envolva as pessoas, a estratégia e as operações da organização. Por isso, Oliveira (2001a) afirma que a qualidade da implantação das estratégias empresariais é resultante de três vertentes: qualidade na formulação das estratégias; qualidade na escolha das estratégias básicas; e qualidade decisória e administrativa da equipe que catalisa e coordena a implantação das estratégias.

Por isso, é preciso que os administradores compreendam que a elaboração e a implantação da estratégia são interdependentes (HREBINIACK, 2006). Mintzberg (1998) corrobora dessa visão quando observa que na maioria das vezes uma estratégia não é realizada por falhas na implantação, pois, segundo o autor, seria necessário ir além e buscar a causa do problema na formulação da estratégia. Nesse caso, os gerentes deveriam ter sido mais prudentes, fazendo com que suas estratégias se desenvolvessem gradativamente, através das ações e experiências da organização. Nesse sentido, o autor defende o uso das chamadas "estratégias emergentes", aquelas que surgem durante a implantação do Planejamento Estratégico, ou seja, as estratégias que não foram antecipadamente elaboradas.

No que tange ao uso de estratégias emergentes, Anon (2009) vai ao encontro de Mintzberg (1998), ao proferir que o mandato do plano estratégico é muito mais abrangente e audacioso do que o simples processo de estabelecimento de um objetivo até o momento em que ele seja atingido para, então, estabelecer outro. De acordo com Anon (2009), "continuous appraisal" é o nome do jogo agora, "avaliação contínua das estratégias", pois observar as necessidades de mudança de rumo é fundamental, não mais como uma aposta de sucesso, mas para a sobrevivência das empresas, pois as crises não esperarão pelo próximo ciclo de Planejamento Estratégico.

Para contribuir com o processo de implantação do Planejamento Estratégico, Breene, Nunes e Shill (2007) acreditam na necessidade da criação de um novo departamento nas empresas, ou um novo cargo, o qual seja exclusivamente responsável por fazer com que o Planejamento Estratégico funcione, dividindo com o presidente essa função.

Kaplan e Norton (2005) denominaram de Office of Strategy Management - OSM essa nova divisão organizacional, responsável pelo Planejamento Estratégico, a qual, segundo os autores, apesar de ser uma importante divisão funcional, não precisa ser grande e nem exige contratação onerosa de pessoal na organização.

Apesar de o processo de implantação do Planejamento Estratégico contar com responsáveis exclusivos, Beer e Eisentat (2000) advogam que a estratégia não se completa por culpa de outros seis fatores, os quais os autores denominaram "assassinos silenciosos". Essa nomenclatura foi escolhida devido à analogia que os autores fazem com o colesterol, chamado pelos doutores da medicina como um "assassino silencioso", que obstrui artérias, sem manifestar nenhum sintoma externo no organismo; assim como nas organizações, em que os assassinos silenciosos trabalham abaixo da superfície, mutuamente reforçando as barreiras que obstruem a execução da estratégia e a aprendizagem organizacional, porque raramente são reconhecidas publicamente ou dirigidas explicitamente.

Os seis assassinos silenciosos definidos por Beer e Eisenstat (2000) são: 1) o estilo top-down da gerência sênior; 2) o estabelecimento de estratégias confusas e prioridades conflitantes; 3) uma equipe ineficaz da gerência sênior; 4) a comunicação vertical ineficiente; 5) a coordenação deficiente de funções e negócios; e 6) o inadequado desenvolvimento de habilidades de liderança para os níveis mais baixos da empresa. Esses autores acreditam que os chamados "assassinos" estão extremamente difundidos nas organizações, porque representam os pontos críticos do stress organizacional, por isso, são necessárias novas capacidades em busca do sucesso e da transição para níveis mais elevados de desempenho, velocidade e capacidade de 
resposta. Contudo, Beer e Eisenstat (2000) ainda defendem que essas barreiras podem ser desobstruídas, desde que o presidente da organização acredite que, para acabar com esses empecilhos, a construção das potencialidades deve ser a chave para o alto desempenho, além disso, o responsável pela organização tem de estar disposto a aprender e acreditar no potencial de seus empregados.

Rodrigues e Leite (2006) defendem que, quando a elaboração do Planejamento Estratégico é realizada juntamente com os colaboradores, por meio de uma gestão mais participativa, a sua implantação torna-se mais fácil e com menos resistências, uma vez que os funcionários compreendem melhor seu papel no Planejamento Estratégico e sentem-se dele participantes; demonstram maior interesse em se envolver nos processos de tomada de decisão, maior autoconfiança e maior capacidade para resolver situações que fogem ao cotidiano; são mais qualificados para assumir responsabilidades adicionais; e se identificam com as metas e objetivos da empresa.

No entanto, de acordo com dados da pesquisa da Bain \& Company (RIGBY e BILODEAU, 2007), o sucesso no uso do Planejamento Estratégico, assim como a propensão a sua utilização por parte dos executivos, está diretamente ligado à capacidade de mensurar e comunicar os resultados obtidos, ou seja, fornecer um feedback aos empregados sobre seu desempenho real, por meio de medidas de desempenho que sejam compatíveis com objetivos e metas organizacionais (ACKOFF, 1982).

Assim, é possível perceber mais claramente a interdependência entre formulação e implantação do Planejamento Estratégico, uma vez que, embora a formulação influencie a avaliação e o controle estratégico, o processo funciona também no sentido contrário, pois uma avaliação eficaz fornece retroalimentação para modificação de padrões inadequados propostos pelo Plano (HREBINIACK, 2006).

O Planejamento Estratégico se mostra como um processo cíclico, sem fim, que por englobar toda a organização se relaciona com todas as partes da empresa e com todos os níveis hierárquicos, dessa forma, influencia e é influenciada por vários fatores organizacionais, como liderança, cultura, estrutura e comunicação.

\section{Os fatores organizacionais estrutura, liderança, cultura e comunicação e a influência que exercem sobre o processo de implantação do planejamento estratégico}

No intuito de compreender melhor o assunto e para responder ao objetivo de pesquisa, o presente artigo primeiramente buscou na teoria o que está sendo dito sobre os fatores a serem estudados - estrutura, liderança, cultura e comunicação - e de que forma esses fatores se relacionam com o Planejamento Estratégico.

A estrutura organizacional é um assunto que precisa receber bastante atenção na administração, uma vez que contribui para todo o funcionamento empresarial e frequentemente está recebendo novas formas de configuração, ou seja, surgem novos tipos de estrutura para as empresas se organizarem. Mintzberg (2003, p. 12) a define como a "soma total das maneiras pelas quais o trabalho é divido em tarefas distintas e, depois, como a coordenação é realizada entre essas tarefas".

A estrutura de uma empresa pode se formar com base em diferentes fatores, como o tamanho da organização, o sistema técnico, o ambiente, a escolha estratégica, o poder e a necessidade entre eficiência e eficácia (HALL, 1984; MINTZBERG, 2003; HREBINIACK, 2006). Não obstante, Hall (1984) e Mintzberg (2003) destacam que a formação da estrutura retrata um quadro relativamente estático da organização, criando a necessidade de acrescentar "movimento" a ela, por meio de processos de integração e compartilhamento das informações, para fazer com que os quadros e as linhas da forma organizacional ganhem vida e obtenham 
algo de valor. Nesse mesmo sentido, Hrebiniack (2006) advoga pela integração e coordenação entre as partes da estrutura, uma vez que todas são interdependentes.

Sapolsky, em 1967, realizou um estudo sobre organização estrutural em lojas de departamento, nos Estados Unidos, focando na estrutura funcional, e já chamava a atenção para o fato de que os profissionais, que estavam na posição de desenhar e redesenhar a estrutura de grandes organizações, encontravam-se em uma difícil posição, pois viviam sob a pressão de desenharem estruturas organizacionais que servissem para fomentar a criatividade de seus funcionários e a inovação; e essa pressão continua existindo, instigando a formação de novas configurações. Hatch (2002) afirma que, à medida que os negócios tornam-se mais adaptáveis e flexíveis, como resposta às constantes variações de oportunidades e demanda em seus mercados globalizantes, os entendimentos tradicionais da estrutura organizacional se esgotam.

Para Ackoff (1982), Tregoe e Zimmerman (1984), Hall (1984), Certo e Peter (1993), Mintzberg (2003) e Hrebiniack (2006), a estrutura, seja qual for o seu desenho na organização, precisa ter o Planejamento Estratégico integrado a ela, para que possa funcionar de forma eficaz.

Hrebianick (2006) profere que o Planejamento Estratégico afeta a estrutura, uma vez que é ele quem define a interdependência entre as unidades, as funções ou as pessoas que devem trabalhar juntas. Do mesmo modo, Spee e Jarzabkowski (2009) afirmam que a estratégia, advinda de um Planejamento Estratégico, é uma ferramenta capaz de interligar a estrutura de uma organização, sendo útil na facilitação das interações sociais dentro da empresa. Oliveira (2001b) e Ackoff (1982), seguindo essa mesma linha, acreditam que a implantação de uma estratégia afeta a estrutura, à medida que a estratégia exige alterações internas na empresa. Entretanto, Hall (1984) argumenta que a estrutura define a estratégia e que a modifica, seguindo o raciocínio de que a definição das estratégias do Planejamento Estratégico é decidida pelas pessoas que estão no poder. Nesse sentido, Hrebianick (2006) destaca que as questões estruturais que afetam a execução da estratégia estão em torno do impacto da forma estrutural da empresa, concluindo que tanto a estrutura afeta a estratégia como é afetada por ela.

Outro fator organizacional a ser estudado no presente artigo é a liderança que, segundo Drucker (2001), é exercida por uma pessoa que possui seguidores, essa pessoa é capaz de fazer com que esses seguidores ajam corretamente. Por isso, um líder não precisa ser necessariamente amado ou admirado, pois "popularidade não é liderança, resultados sim" (DRUCKER, 2006, p. 12).

Partindo da lógica de Drucker (2006), em que o líder é aquele que exerce influência sobre outras pessoas, vale lembrar que a posição hierárquica dentro da empresa não faz do executivo um líder, pois nem todo chefe é líder e nem todo líder é chefe. De acordo com Covey (2000) e Hrebiniack (2006), há pessoas que, mesmo ocupando cargos de chefia, não exercem liderança, o máximo que conseguem é obediência por coação ou por interesses particulares das pessoas a quem chefiam, enquanto há pessoas que exercem influência sobre as outras, independentemente de ocuparem cargos de chefia.

Ainda nesse contexto da liderança, Maccoby (2004) e Vergara (2000) apresentam a importância dos liderados, pois sem eles a liderança não existiria. Cardwell e Tichy (2003) ainda destacam que as empresas que visarem à construção de novos líderes são as que sobreviverão com sucesso no atual mundo competitivo em que vivem hoje as organizações.

No entanto, Pretorius (2009) destaca que, ao assumir o posto, o novo líder tem de enfrentar determinadas responsabilidades, fazendo o possível para cumpri-las da melhor maneira. O autor divide essas responsabilidades em sete categorias: da legitimidade, da falta de conhecimento prévio, de acesso e integridade dos dados, de compartilhar a visão, da construção de um pensamento comum, de controlar o feedback e da cultura. 
Contudo, Tregoe e Zimmerman (1984), Bossidy (2005) e Hrebiniack (2006) argumentam que a presença de uma liderança que acredita na implantação do Planejamento Estratégico, e que faz as "coisas" acontecerem, é primordial para o seu sucesso.

De acordo com Bossidy (2005), um dos elementos que definem uma empresa voltada para a execução se constitui na presença de um líder que conheça bem o seu negócio e seu pessoal, e tenha capacidade de ser mentor de pessoas que em alguma situação possam substituí-lo. Hrebiniak (2006, p. 43), advoga que a liderança "deve motivar o sentimento de pertença com relação ao processo de execução e firmar um compromisso com ele", pois é muito mais fácil executar uma estratégia quando ela tem o apoio de pessoas poderosas.

A cultura organizacional, por sua vez, é, e sempre será, um tema atual e presente, não apenas no debate acadêmico, mas também como motivo de preocupação de administradores e consultores organizacionais. $\mathrm{O}$ termo é motivo de inquietação para muitos autores e administradores que tentam conceituar, entender, aperfeiçoar ou diagnosticar a cultura das organizações. Segundo Pereira e Cunha (2004), a cultura é definida desde parte integrante do próprio processo de administração, como um conjunto de pressupostos que um grupo inventou como forma correta de lidar com problemas, até como um mecanismo de controle.

Para Schein (1984 apud FREITAS 1991), a cultura vai além dos comportamentos observáveis e dos valores que podem ser justificados conscientemente, como normas e crenças, e se caracteriza como a força dos pressupostos subjacentes, tipicamente inconscientes, os quais realmente determinam como os membros de um grupo percebem, sentem e pensam. Nesse sentido, Hrebiniack (2006), Fischer (1996), Demuner (2003) e Freitas (1991) veem a cultura também como um instrumento de poder e controle, pois, como afirma Hrebianiack (2006), a cultura influencia diretamente no comportamento de todos os membros da organização, consequentemente, atingindo seus resultados, sendo muito importante para a empresa.

Gandz (2007) chama a atenção para o fato de que as avaliações de cultura organizacional, em sua maioria, são suspeitas, pois são baseadas em questionários que são manipulados pelos gestores, fazendo com que os funcionários não acreditem no seu valor e fiquem receosos em deixar tudo às claras, mesmo sabendo que esse seria um estudo supostamente anônimo. Já Bossidy (2005) profere que é possível reconhecer sim a cultura das organizações, simplesmente através das atitudes dos seus funcionários, até mesmo em uma simples conversa entre dois deles no corredor da empresa.

No entanto, a cultura nas empresas, segundo Freitas (1991), é um elemento capaz de integrar outros sistemas organizacionais, a fim de ampliar e viabilizar melhores alternativas de sucesso. Segundo Semler (1988), Freitas (1991), Pereira e Cunha (2004), Bossidy e Charan (2002), Hrebiniack (2006), a presença de uma cultura forte, voltada à execução e alinhada com os métodos da implantação do Planejamento Estratégico, influencia na sua eficácia.

A escola de pensamento estratégico, denominada "Escola da cultura empresarial" apresentada por Mintzberg, Lampel e Ahlstrand (2002), também defende que a estratégia está enraizada na cultura da empresa. Do mesmo modo, Freitas (1991) e Gaj (1990) apresentam que o sistema de valores determinado pela cultura organizacional reflete uma concepção racionalizada do que é considerado desejável pelos membros organizacionais, dessa forma, influencia as escolhas de objetivos e estratégias. Porém, autores como Monteiro, Ventura e Cruz (1999) advogam que as características próprias de cada organização nascem das estratégias adotadas por seus dirigentes, a fim de manter a empresa e as pessoas, os dirigentes têm de estar de acordo com esses pressupostos, os quais vão se internalizando, formando uma posição a respeito de "como as coisas são". Ross (2000) acredita que a cultura reflete os valores dos fundadores que estão na visão e missão da empresa, construídas no Planejamento Estratégico.

Pereira e Cunha (2004) advogam que a presença de uma cultura forte voltada à execução e um bom clima organizacional, em toda a organização, são muito importantes para que o Planejamento Estratégico funcione e não fique apenas no papel. Do mesmo modo, Demuner (2003) profere que uma cultura competitiva é 
aquela que apoia a implantação da estratégia e que cultiva o costume de "aprender a aprender", cujos funcionários se comprometem com negócio da empresa, em que todos os membros se desenvolvam em direção e metas afins.

O último fator organizacional a ser estudado é a comunicação que neste novo milênio destacou-se de maneira importante na vida das organizações, até porque deixou de ser considerada despesa e de ser maltratada pelos burocratas que a consideravam descartável e desnecessária para entrar no rol dos bons investimentos e se tornar estratégica e fundamental no processo de tomada de decisões, deixando de ser um mero apêndice do processo de gestão (BUENO, 2003, 2005).

De acordo com Robbins (1978, p. 443), há comunicação apenas quando há a "transferência e compreensão de significados", caso contrário, ela não acontece. No que tange à comunicação organizacional interna, foco deste estudo, Béon (1992) afirma que jamais se veneraram tanto suas ferramentas, pois o público interno está recebendo mais atenção, uma vez que foi compreendida a lógica de que são eles que fazem a empresa acontecer.

Para conseguir atrair todos os tipos de público interno da organização, Quirke (1996) acredita que os comunicadores internos precisarão entender sobre os negócios da organização, possuir conhecimento de mercado e do perfil do público com que a empresa atua, além de mostrar que a comunicação interna pode sim ser usada como uma estratégia de negócios.

Mokler e Gartenfeld (2009) defendem uma das mais novas ferramentas de comunicação organizacional interna, as intranets que, segundo os autores, se implementadas e utilizadas corretamente, oferecem benefícios substanciais que podem contribuir para o sucesso global de uma da organização e para suas estratégias de negócios.

Beón (1992), Bossidy e Charan (2002), Bueno (2003) e Hrebiniack (2006) afirmam que o compartilhamento das informações e a transferência de conhecimento, ou seja, o sistema de comunicação da empresa, também influencia na execução do Planejamento Estratégico.

Do mesmo modo, Rogers, Miller e Judge (1998) asseguram que é preciso que os gerentes prestem especial atenção à necessidade de informação de que as estratégias possuem, pois apenas assim elas poderão ser implantadas com sucesso, contribuindo com o desempenho positivo da organização. Sob essa mesma perspectiva, uma pesquisa, realizada por Brenes, Mena e Molina (2008), com 300 empresas da América Latina, detectou que $90 \%$ delas consideraram essencial para a implantação bem-sucedida de uma estratégia de negócios a presença de uma estratégia clara, possível de ser transmitida e compreendida por todos os membros da organização.

Hrebianiack (2006) ainda destaca a questão de cada profissional saber claramente quais são suas responsabilidades perante o processo de Planejamento Estratégico, pois como afirma Rego (1986, p. 18) "os bons administradores são aqueles que conseguem produzir significações, tanto quanto dinheiro".

\section{Procedimento Metodológico}

A presente pesquisa se caracteriza como um estudo teórico-empírico, realizado através do método indutivo, abordagem de pesquisa qualitativa descritiva e estudo de caso.

O sujeito de pesquisa, escolhido intencionalmente para a realização do presente artigo, trata-se da Empresa Santa Luzia Laboratório Médico, isso devido ao fato dessa empresa obter a principal condição necessária para realização da pesquisa, ou seja, possuir um Plano Estratégico em fase de implantação, além de ser uma 
empresa referência na área em que atua, e, também, devido à oportunidade da pesquisadora ter acesso às diversas fontes de informação e eventos que contribuíram para a realização do estudo.

O universo da organização em estudo conta com 552 funcionários, dessa forma, foram intencionalmente escolhidos os sujeitos da pesquisa de acordo com os objetivos da mesma.

Foi entrevistado o Diretor-Presidente da Empresa Santa Luzia Laboratório Médico e os demais diretores que junto com ele formam o comitê de gestão da organização, totalizando seis diretores, cada qual responsável por uma área da empresa.

Também foram entrevistados gerentes setoriais da organização para, desse modo, identificar os fatores organizacionais em estudo, sob a perspectiva de diferentes níveis hierárquicos. Dentre os 29 gerentes da empresa, oito deles foram selecionados para participar da pesquisa, de acordo com a disponibilidade de tempo de cada um deles e do prazo estabelecido pela pesquisadora.

As entrevistas semiestruturadas com diretores e gerentes foram realizadas no período de 29 de setembro a 16 de novembro de 2009, seguindo um roteiro pré-estabelecido pela pesquisadora, com 62 questões,

Também fizeram parte da pesquisa 14 coordenadoras de postos próprios de coleta. Cada posto próprio de coleta Santa Luzia possui uma pessoa responsável por ele, esse profissional é o "Coordenador do posto de coleta". Esses profissionais contribuíram com a pesquisa à medida que possibilitaram um diagnóstico de como a base da organização se relaciona com o processo de implantação do Planejamento Estratégico, e de que forma consideram as variáveis em estudo - liderança, cultura, estrutura, comunicação - dentro da empresa. O questionário contou com 24 questões fechadas e uma questão aberta, e foi aplicado aos coordenadores no dia 4 de dezembro de 2009.

Vale destacar que os fatores organizacionais escolhidos para a análise foram: liderança, cultura, estrutura e comunicação. Isso se deu pelo fato de tais fatores serem considerados pelos autores da área estratégica, como Hrebiniack (2006), Bossidy e Charan (2002), Mintzberg (2003), Certo e Peter (1993) e Oliveira (2001b), como influenciadores do processo de Planejamento Estratégico.

A análise de conteúdo dos dados foi realizada de forma qualitativa devido à natureza dos dados que foram coletados e os pressupostos teóricos que nortearam a investigação.

\section{Análise dos Dados}

\section{O planejamento estratégico na empresa Santa Luzia Laboratório Médico}

A ferramenta Planejamento Estratégico passou a ser implantada na Empresa Santa Luzia Laboratório Médico em 1998 com o apoio do Diretor-Presidente. Com o passar dos anos, o processo se aperfeiçoou e foi denominado Gestão Estratégica com o intuito de englobar já na sua nomenclatura a implantação. Na Empresa Santa Luzia, a forma de elaboração do Planejamento Estratégico é baseada na metodologia de Oliveira (2001b); a cúpula da organização participa mais efetivamente desse processo, porém, a base hierárquica também é ouvida pela representação de seus diretores e pelos dados colhidos durante as visitas setoriais.

O Planejamento Estratégico, na empresa estudada, é elaborado a partir das perspectivas do Balanced Scored Card (pessoas, finanças, processo e clientes), de Norton e Kaplan (1997). No entanto, a empresa não utiliza esse software no processo de implantação do seu planejamento, pois conta com ferramentas como reuniões de análise crítica, planilhas de acompanhamento e visitas setoriais (o Gerente do Planejamento e o Diretor- 
Presidente anualmente visitam todos os setores da empresa, buscando seus pontos fortes e fracos). A implantação pretende envolver todos os níveis da organização, principalmente através de visitas setoriais, citadas pelos sujeitos da pesquisa como um dos meios que mais envolve a organização, uma vez que atinge também a sua base.

A elaboração e a implantação do Planejamento Estratégico se mostram de maneira integrada na empresa em estudo. Para Hrebiniack (2006), a consciência dos executivos de que a formulação e implantação da estratégia são interdependentes e se influenciam mutuamente contribui para o desenvolvimento do Planejamento Estratégico nas organizações, impedindo que o foco seja apenas na formulação. Ainda, na Empresa Santa Luzia, há flexibilidade para uso de estratégias emergentes, dessa maneira, o processo de Gestão Estratégica evolui a cada ano, e a principal responsável por ele, a gerente do setor, busca, a todo o momento, formas de aperfeiçoar esse processo, contando com a colaboração de todos. Desse modo, naturalmente, o processo apresenta pontos a melhorar, como maior respeito aos prazos de execução e a instalação de um software de acompanhamento que desonere o trabalho dos gestores e auxilie no preenchimento manual das atuais planilhas de acompanhamento.

Vale destacar que, na empresa em estudo, o Planejamento Estratégico é visto como um processo de aprendizado, e esse fator estimula o seu desenvolvimento e permite que melhoras no processo sejam implantadas. De acordo com os autores Kaplan e Beinhockere (2003), Ackoff (1982) e De Geus (1997), transformar o processo do Planejamento Estratégico em aprendizado é uma das principais vantagens competitivas, ao passo que prepara os envolvidos para agir adequadamente diante dos inevitáveis momentos de desafio que o mercado impõe.

\section{A estrutura, liderança, cultura e comunicação na empresa Santa Luzia Laboratório Médico e a influência desses fatores no processo de implantação do planejamento estratégico}

Na Empresa Santa Luzia Laboratório Médico, a estrutura se mostrou bem definida, tanto no que tange a sua divisão de áreas e setores, como no que diz respeito aos níveis hierárquicos da organização. $\mathrm{O}$ desenvolvimento da estrutura da empresa, assim como a organização de seu organograma, deu-se devido ao seu crescimento que contou com a absorção de um grande número de colaboradores, o que vai ao encontro das proposições de Hall (1984), Mintzberg (2003) e Hrebiniak (2006). A empresa possui níveis de tomada de decisão que se formam de acordo com a sua estrutura de poder, ou seja, o Diretor-Presidente tem maior poder de decisão do que os diretores, que possuem maior autoridade sobre os gerentes e assim sucessivamente. Apesar de bem definida, a estrutura da organização em estudo não é rígida e se mostra bem flexível a mudanças de organograma, assim como à aceitação de opiniões vindas da base da organização. Cada um dos setores da organização possui peculiaridades, de acordo com o gestor que o comanda, logo, questões como centralização, formalização e participação variam de acordo com cada setor da empresa, como apresenta Hall (1984). No entanto, as decisões que envolvem a empresa como um todo, como as estratégias macro, são centralizadas no comitê de gestão, e as decisões que tangem somente a determinado setor, assim como as decisões operacionais, são de responsabilidade dos gerentes; e no caso dos postos de coleta, as Coordenadoras possuem autonomia para tomar decisões que dizem respeito aos seus respectivos postos.

No que diz respeito à relação da estrutura organizacional com o Planejamento Estratégico, a teoria apresenta que para que este último seja implantado de forma eficaz, precisa estar integrado ao primeiro (ACKOFF, 1982; TREGOE e ZIMMERMEN, 1984; HALL, 1984; CERTO e PETER, 2003; MINTZBERG, 2003; HREBINIACK, 2006). No estudo empírico, tal premissa se mostra verdadeira, uma vez que sua implantação está em pleno funcionamento devido à integração do planejamento com sua estrutura, pois o planejamento respeita os níveis hierárquicos da organização e se dissemina através deles. Corroborando também com a teoria, na Empresa Santa Luzia, tanto a estrutura afeta o seu Planejamento Estratégico, como este último é 
afetado por ela (HREBINIACK, 2006). A estrutura da Empresa Santa Luzia acaba por afetar o seu planejamento, uma vez que quem delineia as estratégias e a forma de como implantá-las está no topo da hierarquia, assim como são esses indivíduos os mais empenhados para que o planejamento realmente seja executado e a visão da Empresa alcançada. Já o Planejamento Estratégico afeta a estrutura da Empresa Santa Luzia ao passo que ele é capaz de provocar mudanças estruturais, como no caso do setor de Tecnologia e Informação, que está prestes a subir no organograma, por ter se tornado um setor estratégico para a empresa; e no caso da criação de um setor específico para tratar das questões da Gestão Estratégica, o que faz com que o estudo empírico se alinhe às proposições de Ackoff (1982) e Oliveira (2001a). Ainda, na empresa em estudo, o Planejamento Estratégico influencia sua estrutura no sentido de unir mais os setores, pois ao utilizar essa ferramenta, os responsáveis pelo planejamento passaram a trabalhar com base nos mesmos objetivos, e isso causou maior interação entre eles.

Em termos de liderança, na empresa em estudo, a maior liderança é representada pelo seu fundador, atual Diretor-Presidente, o qual apresenta características de um grande líder, principalmente pelo fato de atrair seguidores, uma vez que Drucker (2006) defende que líder é a pessoa que possui seguidores, sendo capaz de fazer com que elas ajam corretamente. Com esta pesquisa desenvolvida foi possível perceber que o DiretorPresidente é admirado pelas pessoas que trabalham com ele, já que se observou que elas sentem orgulho em servi-lo e confiam nele. Em contrapartida, o Diretor-Presidente busca estar presente em todos os níveis hierárquicos da organização, e confia nos seus liderados, delegando-lhes tarefas e acreditando nos seus projetos, principalmente nos diretores, os quais o representam. Nesse sentido, vale mencionar a contribuição de Maccoby (2004) quando afirma que para que alguém lidere é preciso não só um talento excepcional, mas principalmente a capacidade de atrair seguidores, o que poucos dos entrevistados nesta pesquisa demonstraram estar preocupados.

Além do Diretor-Presidente, obviamente outros líderes podem ser encontrados na empresa estudada, inclusive ocupando cargos de chefia, o que vai ao encontro do que dizem Hrebiniack (2006) e Drucker (2006) que reconhecem as diferenças entre gerência e liderança, defendendo que existe poder além da hierarquia. Ainda vale mencionar que os diretores e gerentes entrevistados possuem, cada um, o seu estilo de liderança, e o desenvolvem de acordo com o que acreditam serem as características e responsabilidades de um líder, visto que, de acordo com Drucker (2006), a liderança é uma habilidade que pode ser desenvolvida com o tempo. Entretanto, alguns gestores da Empresa Santa Luzia ainda se dedicam muito ao operacional e se esquecem um pouco da gestão.

O caso da Empresa Santa Luzia está alinhado também com o que afirmam Tregoe e Zimmerman (1984), Bossidy (2005), Hrebiniack (2006), Gaj (1990), Certo e Peter (1993), ao citarem que a presença de uma liderança confiante na implantação do Planejamento Estratégico e que faz com que as coisas aconteçam é primordial para o seu sucesso. No estudo empírico, a principal liderança da empresa, o Diretor-Presidente, está envolvida com o processo de Planejamento Estratégico desde sua primeira elaboração, tanto que a atual visão da empresa representa uma aspiração sua. Da mesma forma, a coalizão dominante formal, diretores e gerentes, também está envolvida nesse processo. Percebeu-se que quanto mais alto o cargo, maior o envolvimento do profissional com a implantação do Planejamento Estratégico; diretores e gerentes, mas, principalmente, os diretores, o que envolve também o Presidente da organização, acreditam na ferramenta Planejamento Estratégico, o que o deixa ao lado da estrutura de poder, haja vista que de acordo com Hrebiniack (2006, p. 27) "os programas de execução que entram em contradição com a estrutura de poder, ou com a influência de uma organização, estão condenados ao fracasso". O estudo empírico também se mostra alinhado às proposições de Ackoff (1982), Covey (2000), Bossidy e Charan (2002) e Hrebiniack (2006), à medida que demonstra maturidade da organização no seu processo de implantação, pois a coalizão dominante se mostra capaz de delegar tarefas, distribuindo assim responsabilidades que, de acordo com os autores, trata-se uma das principais funções do líder no processo de implantação do planejamento, a qual é feita devido à confiança depositada nos empregados. Para Hrebiniack (2006), Bossidy (2005) e Oliveira (2001a), também uma das principais funções do líder é motivar seus funcionários a atingirem os objetivos propostos pelo planejamento. Esses autores destacam que o incentivo financeiro é o mais esperado pelos funcionários, no entanto, na empresa em estudo, a motivação dos liderados é realizada com base na 
valorização do colaborador e no reconhecimento de que seu trabalho contribuirá para que a empresa alcance seus objetivos.

Observando outro fator estudado, pode-se averiguar que a cultura da Empresa Santa Luzia Laboratório Médico sofreu grande influência do seu fundador, tanto que os valores que a guiam até hoje seguem os princípios do Diretor-Presidente, o que vai ao encontro das proposições de Demuner (2003) e Schein (1996) quando afirmam que os fundadores de uma empresa exercem um impacto importante na sua cultura inicial. A cultura da empresa estudada mostrou-se forte e enraizada, já que todos os que participaram da presente pesquisa a definiram com base nos mesmos princípios, fator este que pode explicar a teoria de Freitas (1991). A Teoria desse autor defende que empresas que trabalham com uma única linha de produtos, no caso do estudo empírico de serviço, terão mais êxito se contarem com uma cultura uniforme, visto que todos os entrevistados da Empresa Santa Luzia acreditam que a cultura da organização contribui para que sejam atingidos resultados positivos.

Devido à cultura forte da organização, que está presente no dia a dia dos colaboradores, a formação de subculturas é pequena. O que recebe destaque é a diferença de cultura pessoal que existe entre a área Técnica-Científica e a Administrativa, pelo fato da primeira ser a área afim da organização, e devido à diferente formação acadêmica dos profissionais, pois como profere Schein (apud FLEURY, 1996), grupos com ocupações semelhantes tendem a desenvolver culturas próprias no interior das organizações. Porém, no estudo empírico, a cultura geral da organização se mostra mais forte, o que vai ao encontro do que diz Hrebiniack (2006), quando ele afirma ser possível que prevaleça uma cultura forte sobre as várias subculturas das unidades, uma vez que a cultura produz e reforça os comportamentos dentro das organizações, que, por sua vez, afetam o desempenho organizacional de maneiras essenciais, da mesma forma que ocorre no estudo empírico.

Semler (1988), Freitas (1991), Pereira e Cunha (2004), Bossidy e Charan (2002) e Hrebiniack (2006) sustentam que a presença de uma cultura forte voltada à execução e alinhada com os métodos da implantação do Planejamento Estratégico influenciam na sua eficácia. Essa constatação é clara no caso da Empresa Santa Luzia, cuja cultura organizacional se mostrou de acordo com o Planejamento Estratégico, e, assim como a estrutura, a cultura da mesma forma que o influencia também é influenciada por ele. A cultura organizacional influenciou já no primeiro Planejamento Estratégico da Empresa Santa Luzia, o qual foi elaborado apenas pela coalizão dominante, cujos valores definidos, que guiam a cultura da organização, foram baseados nos princípios do seu Diretor-Presidente, do mesmo modo que Ross (2000) afirma que os valores dos fundadores se refletem na visão e na missão da empresa construídas no Planejamento Estratégico, embora, hoje, o planejamento incentive a participação e o envolvimento de todos os funcionários na reelaboração dos valores da organização. Desse modo, o estudo empírico alinha-se à premissa de Gaj (1990), Freitas (1991) e Mintzberg et al. (2002) que citam que a cultura organizacional influencia na forma como o processo de Planejamento Estratégico se realiza. Em contrapartida, o Planejamento Estratégico influenciou a cultura da Empresa Santa Luzia, à medida que a fortaleceu e diminuiu a distância que existia entre os setores. Do mesmo modo que começou a implantar uma cultura de maior transparência na organização, maior compartilhamento de informações, além de iniciar na empresa o hábito de sempre planejar. Dessa forma, o estudo de caso também está alinhado à teoria de Monteiro et al. (1999) e Ross (2000).

No que diz respeito à comunicação interna da Empresa Santa Luzia Laboratório Médico - fator organizacional estudado - os colaboradores da empresa a veem como um sistema em constante evolução. Formalmente, a comunicação acontece através de quatro canais: os jornais internos, a Intranet, os grupos de $e$-mail e as reuniões. No que se refere aos canais de comunicação interna, a teoria mostra a importância de segmentar o público interno, uma vez que seus membros possuem interesses diferentes dentro da organização (BUENO, 2003), assim como a importância de manter esses meios integrados (CRUZ, 2007). Na Empresa Santa Luzia, os meios de comunicação interna são segmentados de acordo com o público ao qual a informação se destina, através dos diferentes canais, entretanto, alguns colaboradores afirmam que ainda há falta de integração entres esses canais. Devido à segmentação de públicos, há, na organização em 
estudo, informações que ficam retidas com a coalizão dominante formal da organização, que, segundo Bueno (2003), consiste na dificuldade das empresas em partilhar informações e conhecimentos; porém, na empresa em foco, já há ações no sentido de capacitar os colaboradores, principalmente os gerentes, para que eles possam receber um maior número de informações. Dessa forma, de acordo com Robbins (1978), a organização acaba por criar barreiras ou ruídos que prejudicam o perfeito funcionamento da comunicação, ou seja, na organização em estudo, a "rádio-corredor" inevitavelmente também faz parte da sua comunicação interna, mas, às vezes, acaba extrapolando a sua estrutura, fazendo com que o público externo também faça parte dela. Contudo, os colaboradores possuem confiança na comunicação da empresa, acreditam nos comunicados internos e não se envolvem com "comunicados externos".

De qualquer forma, pôde-se perceber que a comunicação entre o topo e a base da organização acontece sem dificuldade nos dois sentidos, principalmente pelo fato de o Diretor-Presidente visitar as bases da organização e se dispor a ouvir todos os colaboradores, exercendo o que, segundo Robbins (1978) e Béon (1992), é uma das habilidades comunicativas mais importantes: o ouvir. Porém, há certos conflitos quando o assunto é comunicação lateral (entre os setores).

O compartilhamento das informações e a transferência de conhecimento, ou seja, o sistema de comunicação da empresa, também influencia na execução do Planejamento Estratégico, conforme a teoria de Beón (1992), Bossidy e Charan (2002), Bueno (2003) e Hrebiniack (2006), e inclusive de acordo com o que foi apresentado no estudo de caso. A comunicação na empresa estudada, durante o processo de Planejamento Estratégico, é realizada em efeito cascata, ou seja, o comitê de gestão (Diretor-Presidente e diretores), que detém as informações que dizem respeito a toda organização, repassa as informações cabíveis aos seus gestores, que, por sua vez, são os responsáveis por transmití-las aos seus colaboradores. Assim, a comunicação com as bases inferiores da organização, além de ser efetuada através das reuniões de cada gerente com seus colaboradores, acontece também por meio de visitas setoriais, das quais participam o Diretor-Presidente, a Gerente da Gestão Estratégica e sua diretora. A Gerente da Gestão Estratégica acompanha todo esse processo de comunicação, com especial atenção à área técnica, que, por sua formação acadêmica, necessita de maior respaldo. Por meio da pesquisa constatou-se que a principal fonte de divulgação do Planejamento Estratégico na Empresa Santa Luzia é a pessoal, ou seja, as reuniões que acontecem entre os diferentes níveis hierárquicos da organização; o jornal interno da empresa, "O Santinha", e a Intranet foram os outros canais citados, pelos quais a base da organização recebe as informações a respeito do planejamento.

Para Cruz (2007), as organizações deveriam delinear estratégias de comunicação considerando os fluxos pelos quais as mensagens são transmitidas e alinhando-as ao Planejamento Estratégico da organização. No entanto, na empresa estudada, não faz parte do Planejamento Estratégico delinear estratégias para sua divulgação, todavia, quando os diretores ou gestores as elaboram sem a participação dos colaboradores, automaticamente, já pensam no seu entendimento, o que vai ao encontro do que diz Rego (1986, p. 31): "gerar consentimento, eis a meta final da comunicação organizacional"; e do que diz Tregoe e Zimmerman (1984), que proferem que a comunicação cria a aceitação das estratégias quando o seu enunciado é claro, simples e específico. Porém algumas estratégias da empresa estudada ainda são mantidas em sigilo pelo comitê de gestão, fato este indicado por Béon (2003) e Cabestré, Graziadei e Filho (2008) como um dos grandes desafios que as organizações enfrentam.

\section{Conclusão}

Este estudo avaliou como os fatores liderança, cultura, estrutura e comunicação organizacional influenciam no processo de implantação do Planejamento Estratégico, baseando-se em um caso empírico: a Empresa Santa Luzia Laboratório Médico. A ideia central foi investigar a ferramenta organizacional Planejamento Estratégico, com ênfase na sua implantação, identificando os modelos propostos pela literatura. Desse modo, 
foi possível analisar como os fatores liderança, cultura, estrutura e comunicação organizacional, também segundo a literatura, influenciam no processo de implantação do Planejamento Estratégico para, então, descrever como foi realizado o Planejamento Estratégico na Empresa Santa Luzia Laboratório Médico e quais ações estão sendo desenvolvidas para implantá-lo. Depois disso, foi avaliado, na prática, como os fatores em estudo afetam a condução da implantação do Planejamento Estratégico empiricamente, comparando com o proposto pela teoria.

Primeiramente, pôde-se concluir que, assim como apresenta a literatura analisada, o estudo de caso demonstrou que os fatores organizacionais estrutura, liderança, cultura e comunicação se inter-relacionam, pois um influencia na formação do outro.

Na organização em estudo, a estrutura organizacional se apresentou como o fator que mais influencia nos demais, uma vez que a divisão entre áreas e setores que ela desenha acaba por interferir na cultura da empresa, em sua liderança e, também, na comunicação. A estrutura afetou a cultura organizacional da Empresa Santa Luzia, pois as divisões de áreas facilitaram a formação de subculturas. Na liderança, a estrutura interfere, à medida que muitos gestores, considerados líderes, acabam por dedicar mais tempo ao operacional do que ao gerencial devido à estrutura enxuta da organização, ou seja, devido ao pequeno número de colaboradores, os gestores acabam por desenvolver as tarefas operacionais. Quanto à comunicação, a estrutura a influencia na Empresa Santa Luzia, ao passo que os níveis hierárquicos muitas vezes complicam a chegada da informação à base da empresa.

Entretanto, a comunicação também influencia na estrutura, uma vez que os diversos canais têm contribuído para integrar suas diversas partes, assim como a comunicação é o espelho da sua cultura organizacional, o que vai ao encontro do exposto por Bueno (2003). A cultura da Empresa Santa Luzia, por sua vez, é completamente influenciada pela maior liderança da organização, já que foi formada e continua a ser guiada pelos valores do seu Diretor-Presidente. A liderança também influencia a estrutura da empresa, visto que cada departamento possui suas peculiaridades de acordo com o seu líder que acaba formando a estrutura de seu setor, formalizando-a mais ou menos, ou centralizando mais ou menos as decisões.

Respondendo ao objetivo geral da pesquisa, pode-se afirmar que os fatores organizacionais em estudo estrutura, liderança, cultura e comunicação - influenciam a implantação do Planejamento Estratégico da Empresa Santa Luzia Laboratório Médico, da mesma forma que este último as influencia. Entretanto, podese perceber que os fatores em estudo não apenas influenciam a implantação do Planejamento Estratégico, como também são influenciadas por ele, da mesma forma como expôs a teoria que o presente estudo de caso confirmou.

Em síntese, os fatores organizacionais estudados - estrutura, liderança, cultura e comunicação - e o Planejamento Estratégico possuem uma estreita relação, pois se influenciam mutuamente. A Figura 1 representa essa relação: 
Figura 1

Esquema da relação entre os fatores organizacionais - estrutura, cultura, liderança e comunicação - e o processo de Planejamento Estratégico

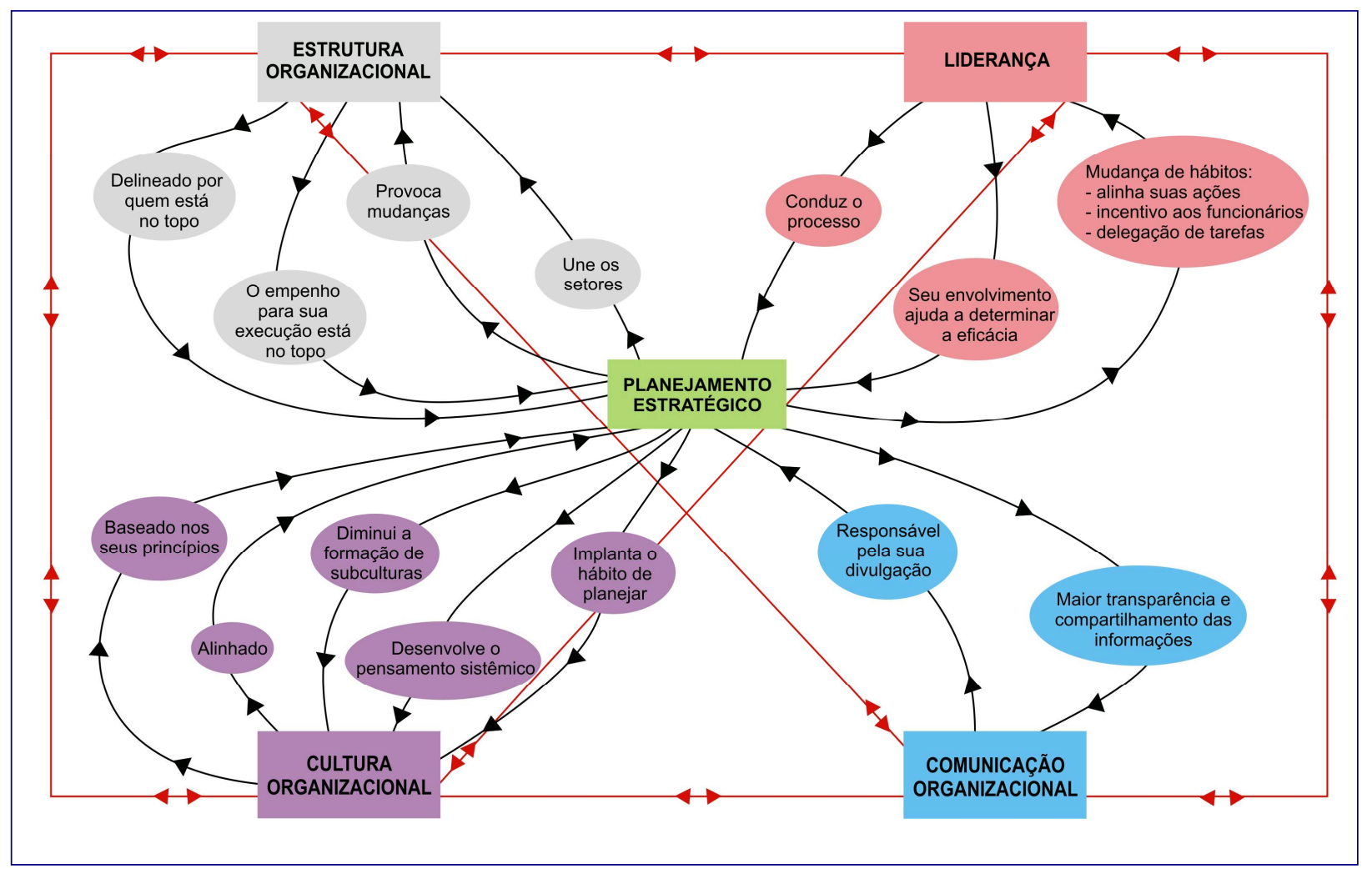

Fonte: Elaborado pelos autores.

Como demonstra a Figura 1, a estrutura influenciou o Planejamento Estratégico na Empresa Santa Luzia, à medida que a maioria das decisões é tomada pelos profissionais que estão no topo da hierarquia, e foi influenciada pelo planejamento, ao passo que criou um setor específico para cuidar das questões estratégicas, do mesmo modo que proporcionou uma maior integração entre os setores, a partir do momento que eles passaram a buscar os mesmos objetivos.

A comunicação organizacional influenciou o processo em estudo, uma vez que seus canais foram os responsáveis por sua divulgação e, também, sofreu sua influência, haja vista que os colaboradores se mostraram satisfeitos em saber qual o rumo que a empresa quer tomar. Ainda, as informações se tornaram mais transparentes e a coalizão dominante passou a se preocupar em preparar seus colaboradores para receberem mais informações.

O fator organizacional liderança influenciou no processo de Planejamento Estratégico da Empresa Santa Luzia, pelo fato de ter sido elaborado e acompanhado, em grande parte, pelos líderes da organização, o que denota o envolvimento da liderança no processo. Em contrapartida, a liderança foi influenciada por ele à medida que a coalizão dominante passou a se preocupar com alinhamento de suas ações ao Planejamento Estratégico.

A cultura da organização estudada, por sua vez, influenciou o planejamento por causa da forte presença dos valores do seu principal líder, fundador da organização e, também, no alinhamento das estratégias e formas 
de implantação com esses valores, enquanto a influência do planejamento na cultura foi percebida por meio da presença do pensamento sistêmico desenvolvido pelos colaboradores, depois que passaram a usar a ferramenta.

Com isso, pode-se afirmar que embora haja uma mútua influência entre todos os fatores organizacionais estudados e o Planejamento Estratégico, a estrutura e a comunicação da organização demonstraram sofrer maior influência do Planejamento Estratégico do que os outros dois fatores; a liderança e a cultura demonstraram mais influenciar no processo de planejamento do que receber influência dele, principalmente a cultura. Percebe-se que a cultura voltada ao aprendizado da Empresa Santa Luzia Laboratório Médico é o principal fator que permite a implantação do seu Planejamento Estratégico, pois permite que o planejamento influencie na sua comunicação e estrutura, uma vez que o Diretor-Presidente cultiva os princípios dessa cultura, haja vista que aceita novas ideias, respeita seus funcionários, delega responsabilidades e busca o envolvimento de todos.

Ainda, com o estudo de caso, é possível constatar que os fatores organizacionais, por estarem integrados ao Planejamento Estratégico, não apenas contribuem para sua implantação, mas também apresentam determinadas limitações.

$\mathrm{Na}$ empresa estudada, a estrutura acaba por atrapalhar a implantação do Planejamento Estratégico, ao passo que há uma grande divisão de setores, e o gestor de cada um desses setores conduz o processo da sua maneira. Mesmo que haja a padronização dos métodos de acompanhamento, cada gestor decide qual a participação dos colaboradores no processo, alguns acompanham e incentivam mais seus colaboradores, enquanto outros são mais descréditos e, dessa forma, não são todos os colaboradores que trabalham com o planejamento na mesma intensidade. A estrutura também acaba causando problemas na comunicação lateral (entre as áreas e os setores), o que é reforçado pelas subculturas.

A cultura da empresa, por ser enraizada e voltada ao aprendizado e receptiva às boas ideias, não demonstra ser um fator limitante para a implantação do Planejamento Estratégico, no caso estudado. Entretanto, a cultura pessoal dos colaboradores pode dificultar o processo, uma vez que os profissionais da área TécnicaCientífica precisam estar envolvidos, mas devido à sua graduação acadêmica, a primeira vez que entraram em contato com o Planejamento Estratégico foi na organização, e isso traz dificuldades no momento da implantação.

A liderança também pode causar determinados infortúnios à implantação, uma vez que diversos gerentes ainda não exercem liderança e gastam a maior parte do seu tempo com o operacional, deixando a gestão em segundo plano, e como o Planejamento Estratégico faz parte da gestão, também ele fica de lado. Além disso, a partir do momento que o nível desce do comitê de gestão, presidente e diretores, os gerentes da empresa já não têm preparo suficiente para receber e compreender todas as informações do planejamento, por isso, tais informações acabam retidas no nível superior. Com esta pesquisa, foi possível perceber que a diretoria da organização estudada está realmente inteirada de todas as partes do Planejamento Estratégico, e os gerentes nem tanto, e estes últimos se incomodam com isso, tanto pela falta de participação, quanto pela falta de interação entre eles.

Outro aspecto interessante observado é que no nível de gerência se encontram os profissionais capazes de fazer críticas ao processo de Planejamento Estratégico da Empresa Santa Luzia que reivindicam mais participação. Já entre as coordenadoras de postos próprios de coleta, que representam a base da organização, parece estar tudo muito bem, sem a necessidade de melhoras no que tange ao Planejamento Estratégico, ou seja, não há muito questionamento na base da organização quanto a esse processo, isso talvez poderia ser explicado pela alienação destes últimos profissionais sobre vários fatores que envolvem o planejamento.

Desse modo, problemas com a comunicação também são enfrentados na empresa estudada, uma vez que não são todos os níveis da organização que já estão cientes da Gestão Estratégica, e isso não se refere apenas à 
base da organização. Ao nível gerencial já há confusões, como foi possível perceber através da dificuldade que os gerentes entrevistados tiveram em definir qual a visão da empresa e como essa visão será mensurada.

Mas, apesar dessas dificuldades, pode-se deduzir que o Santa Luzia Laboratório Médico é uma empresa de sucesso no que tange ao seu processo de Planejamento Estratégico, pois evoluiu rapidamente e aponta inovações positivas.

Com base no exposto pela literatura, pode-se concluir que o caso estudado representa uma organização voltada para a execução, uma vez que os fatores colocados pelos autores já citados, fazem dessa empresa uma empresa voltada à execução, pois estão presentes: uma liderança ativa e envolvida no processo, o alinhamento com a cultura organizacional e a integração com a estrutura e sua divulgação. Porém, o pensamento estratégico, em todos os níveis organizacionais ainda não foi alcançado, mas está caminhando nesse sentido.

Por fim, diante das conclusões expostas, pode-se sugerir à empresa formas de incrementar o processo de implantação do Planejamento Estratégico, a começar pela divulgação e envolvimento de todos os colaboradores nesse processo. Sugere-se a elaboração de um folheto, ou uma cartilha, com todo o Plano Estratégico do biênio, que deve ser entregue a cada um dos colaboradores; sugere-se, ainda, a elaboração de materiais com linguagens apropriadas ao nível de instrução dos funcionários. Ressalta-se, também, que devido ao fato de o contato pessoal ter sido apontado como principal meio pelo qual a base recebe e memoriza as informações do Planejamento Estratégico, a empresa poderia, ao início de cada biênio, realizar um evento com todos os colaboradores para divulgar o Plano Estratégico e, ao final desse ano, poderia promover um novo evento expondo seus resultados. Se a visão for alcançada, a organização poderia financiar uma festa aos colaboradores em agradecimento pelo esforço de cada um, isso os estimularia a se envolverem mais nesse processo.

Outra sugestão é aproveitar a vontade que os gerentes possuem em participar mais do Planejamento Estratégico e realizar reuniões de análise crítica entre eles, assim como reuniões em que eles poderiam apresentar e discutir as metas e estratégias que desenvolveram para os seus setores, o que poderia enriquecer o processo de planejamento, pois isso contribuiria para a criação de uma visão sistêmica mais forte.

Porém, essas propostas são apenas sugestões diante das interessantes práticas que a empresa adota para a implantação do Planejamento Estratégico e podem servir de exemplo para muitas outras instituições, que, ao contrário do caso estudado, não conseguem fazer seu Plano Estratégico sair do papel.

O caso estudado mostra uma empresa que está implantando o seu Planejamento Estratégico e a influência dos fatores organizacionais: estrutura, liderança, cultura e comunicação nesse processo, os quais demonstraram tanto influenciar o processo de implantação, como serem influenciados por ele, assim como demonstraram facilitar a implantação e também limitá-la em diferentes situações.

Assim, recomenda-se uma análise de empresas que também estão implantando o Planejamento Estratégico, no sentido de identificar similaridades, ou seja, observar de que forma os fatores organizacionais aqui estudados influenciam no processo de planejamento dessas empresas. Outra recomendação seria um estudo para identificar demais fatores organizacionais que possam vir a influenciar a implantação do Planejamento Estratégico, como a inovação e a tecnologia, por exemplo. 


\section{Referências}

ACKOFF, R. L. Planejamento Empresarial. Rio de Janeiro: LTC - Livros técnicos e Científicos Editora S.A., 1982.

AMOROSO, R. Lidando com o pensamento estratégico. In: COSTA, B. K.; ALMEIDA, M. I. R. (Coord). Estratégia: perspectivas e aplicações. São Paulo: Atlas, p.31-52, 2002.

ANON, A. Strategic steering to avoid the turbulence: businesses should always be prepared to alter course. Strategic Direction, v. 25, n. 7 p. 24-26, 2009.

BEER, M.; EISENSTAT, R. A. The silent killers of strategy implementation and learning. Sloan Management Review, v. 41, n. 4, p. 29-40, Summer, 2000.

BEÓN, P. Como Desenvolver a Comunicação na Empresa. Portugal: Publicações Europa-América, 1992.

BOSSIDY, L. A receita da execução. HSM Management, v. 4, n. 51, Ano 9, p. 40-44, jul./ago., 2005.

.; CHARAN, R. Desafio: fazer acontecer, a disciplina de execução nos negócios. 3. ed. Rio de Janeiro: Negócio Editora, 2002.

BREENE, R. T.; NUNES, P.F.; SHILL, W. E. The chief strategy officer. Harvard business review, v. 85, n. 10, oct. 2007. Disponível em:

<http://find.galegroup.com/itx/paginate.do?qrySerId=Locale $\% 28 \mathrm{en} \% 2 \mathrm{CUS} \% 2 \mathrm{C} \% 29 \% 3 \mathrm{AFQE} \% 3 \mathrm{D} \% 28 \mathrm{JN} \% 2 \mathrm{CNone} \%$ 2C25\%29\%22Harvard+Business+Review\%22\%3AAnd\%3ALQE\%3D\%28DA\%2CNone\%2C8\%2920071001\%24\&in PS=true\&searchType=PublicationSearchForm\&prodId=AONE\&userGroupName=capes49>. Acesso em: 28 jun. 2009.

BRENES, E. R.; MENA, M.; MOLINA, G. E. Key success factors for strategy implementation in Latin America. Journal of Business Research, n. 61, p. 590-598, 2008.

BUENO, W. C. Comunicação Empresarial: Teoria e Pesquisa. São Paulo: Monole, 2003.

A comunicação empresarial estratégica: definindo os contornos de um conceito. Conexão - Comunicação e Cultura, v. 4, n. 7, p. 11-20, 2005.

CABESTRÉ, S. A.; GRAZIADEI; T. M.; FILHO, P. P. Comunicação estratégica, sustentabilidade e responsabilidade sócio-ambiental: um estudo destacando os aspectos teórico-conceituais e práticos. Conexão - Comunicação e Cultura, v. 7, n. 13, p. 39-58, jan./jun. 2008.

CARDWELL, N.; TICHY, N. M. Feitas para o sucesso: como grandes líderes ensinam suas empresas a vencer. Rio de Janeiro: Campus, 2003.

CERTO, S. C.; PETER, J. P. Administração Estratégica: planejamento e implementação da estratégia. São Paulo: Makron Books, 1993.

COLENCI, A.; GUERRINI, F. M. Organizações voltadas para o aprendizado. In: CAVALCANTI. M. (Org.). Gestão Estratégica de Negócios: evolução, cenários, diagnóstico e ação. São Paulo: Pioneira, 2003.

COVEY, S. R. Mentalidade e habilidades de um líder. In: HESSELBEIN, F.; GOLDSMITH, M.; SOMERVILLE, I. Liderança para o século XXI. São Paulo: Futura, p. 159-168, 2000.

CRUZ, C. M. L. Comunicação Organizacional e pressupostos de comunicação integrada: a experiência em uma universidade na implementação/reestruturação do jornal institucional. Conexão - Comunicação e Cultura, v. 6, n. 11, p. 193-209, jan./jun. 2007.

De GEUS, A. Planejamento como aprendizado. In: STARKEY, K. Como as organizações aprendem. São Paulo: Futura, 1997. 

$\overline{95-110}, 2000$.

A empresa viva. In: Harvard Business Review. Estratégias para o crescimento. Rio de Janeiro: Campus, p.

DEMUNER, S. A importância em se desenvolver uma cultura de aprendizagem nas organizações modernas. UNESC em Revista, v. 6, n. 13, p. 151-168, 2003.

DRUCKER, P. Prefácio. In: HESSELBEIN, F.; GOLDSMITH, M.; BECKHARD, R. O líder do futuro. Prefácio Peter Drucker Fundation. São Paulo: Futura, 2006.

FISCHER, R. M. O Círculo do Poder - As Práticas Invisíveis de Sujeição nas Organizações Complexas. In: FLEURY, M. T. L.; FISCHER, R. M. Cultura e Poder nas Organizações. 2. ed. São Paulo: Atlas S.A, p. 65-88, 1996.

FREITAS, M. E. Cultura Organizacional: formação, tipologias e impacto. São Paulo: McGraw-Hill Ltda, 1991.

FRENCH, S. Critiquing the language of strategic management. Journal of Management Development, v. 28 n. 1 , p. 6-16, 2009.

GAJ, L. Tornando a administração estratégica possível. São Paulo: MacGraw-Hill, 1990.

GANDZ, J. A culture of candor. Ivey Business Journal Online, nov./dez. 2007. Disponível em: <http://find.galegroup.com/itx/start.do?prodId=AONE>. Acesso em: 21 ago. 2008.

HALL, R. H. Organizações: estrutura e processos. 3. ed. Rio de Janeiro: Prentice-Hall do Brasil, 1984.

HATCH, M. J. Explorando os espaços vazios: jazz e estrutura organizacional. Revista de Administração de Empresas, v. 42, n. 3, p. 19-35, jul./set. 2002.

HREBINIAK, L. G. Fazendo a estratégia funcionar: o caminho para uma execução bem-sucedida. Rio Grande do Sul: Bookman, 2006.

KAPLAN, R. S.; NORTON, D. P. A estratégia em ação: balanced scorecard. 5. ed. Rio de Janeiro: Campus, 1997. ; _ـ_ O departamento de gestão estratégica. Harvard Business Review, v. 83, n. 10, p. 48-56, out. 2005. set./out., 2003.

BEINHOCKERE, E. D. Os heróis do Planejamento Estratégico. HSM Management, n. 40, ano 7, p. 40-45,

MACCOBY, M. Por que seguimos os líderes: o poder da transferência. Harvard Business Review, v. 82, n. 9, p. 5968, set. 2004.

MINTZBERG, H. A criação artesanal da estratégia. In: MONTGOMERY, C. A.; PORTER, M. E. Estratégia: a busca da vantagem competitiva. Rio de Janeiro: Campus, p. 419-437, 1998.

.; LAMPEL, J.; AHLSTRAND, B. Safári de Estratégia. Porto Alegre: Bookman, 2000.

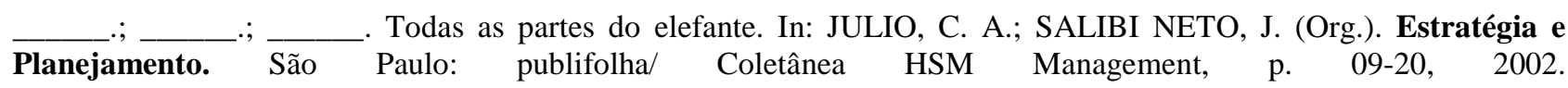

Criando organizações eficazes: estruturas em cinco configurações. 2. ed. São Paulo: Atlas, 2003.

MOCKLER, R. J.; GARTRNFELD, M. E. Intranets: a key element in acompany's e-business strategy. Strategic Change, n. 18, p. 15-26, 2009.

MONTEIRO, C. D.; VENTURA, E. C.; CRUZ, P. N. Cultura e Mudança Organizacional: em busca da compreensão sobre o dilema das organizações. Caderno de Pesquisa em Administração, v. 1, n. 8, p. 69-80, $1^{\circ}$ trim./1999. 
OLIVEIRA, D. P. R. Estratégia empresarial \& vantagem competitiva: como estabelecer, implementar e avaliar. 3. ed. São Paulo: Atlas, 2001a.

Planejamento Estratégico: conceitos, metodologia, práticas. 16. ed. São Paulo: tlas, 2001 b.

PEREIRA, M. F. Planejamento Estratégico: teorias, modelos e processos. São Paulo: Atlas, 2010.

; CUNHA, M. S. Os aspectos da cultura organizacional em um processo de gestão não materialista. In: LANER, A. S.; CRUZ JÚNIOR, J. B. Repensando as organizações - da formação à participação. Florianópolis: Fundação Boiteux, p. 317-338, 2004.

PORTER, M. E. O que é estratégia? In: PORTER, M. E. Competição = on competion: estratégias competitivas essenciais. Rio de Janeiro: Campus, p. 46-82, 1999.

PRETORIUS. M. New ideas in leadership practice, leadership liabilities of newly appointed managers: arrive prepared. Strategy \& Leadership, v. 37, n. 4, p. 37-4, 2009.

QUIRKE, B. Putting communication on management's agenda. Journal of Communication Management, v. 1, ed.1, p. 67-79, 1996.

REGO, F. G. T. Comunicação empresarial, comunicação institucional: conceitos, estratégias, sistemas, estrutura, planejamento e técnicas. São Paulo: Summus Editorial, 1986.

RIGBY, D; BILODEAU, B. Management Tools and trends 2007. Bain \& Company, 2007.

ROBBINS, S. P. O Processo administrativo: integrando teoria e prática. São Paulo: Editora Atlas, 1978.

RODRIGUES, E.; LEITE, F. T. Planejamento Estratégico: uma oportunidade para a participação. Revista Gestão, ano 7, n. 13, Salvador, jan./jun. p. 32-45, 2006.

ROGERS, P. R.; MILLER, A.; JUDGE, W. Q. Using information-processing theory to understand planning/performance relationships in the context of strategy. Strategic Management Journal, n. 20, p. 567-577, 1999.

ROSS, D. N. Does Corporate Culture Contribute to Performance? American International College Journal of Business, 2000. Disponível em: <http://find.galegroup.com/itx/start.do?prodId=AONE>. Acesso em: 21 ago. 2008.

SAPOLSKY, H. M. Organizational Structure and Innovation. The Journal of Business, v. 40, n. 4, p. 497-510, Oct 1967. Disponível em: <http://www.jstor.org/stable/2351631>. Acesso em: 22 ago. 2009.

SCHEIN, E. Liderança e Cultura Organizacional. In: DRUCKER, P. F. O Líder do futuro. São Paulo: Futura, 1996.

SEMLER, R. Virando a própria mesa. São Paulo: Best Seller, 1988.

SPEE, A. P.; JARZABKOWSKI, P. Strategy tools as boundary objects. Strategic Organization, v. 7(2), p. 223-232, may. 2009.

TREGOE, B. B.; ZIMMERMAN, J. W. A estratégia da alta gerência: o que é e como fazê-la funcionar. 2. ed. Rio de Janeiro: Zahar Editores, 1984.

ULRICH, D. Credibilidade x Competência. In: DRUCKER, P. F. O Líder do futuro. 9. ed. São Paulo: Futura, p. $213-$ 222, 2001.

VERGARA, S. C. Gestão de pessoas. São Paulo: Atlas, p. 73-105, 2000.

WHITTINGTON, R. O que é estratégia. São Paulo: Thomson, 2002. 